\title{
New Tubulin Inhibitors from Plants - A Critical Assessment
}

\author{
Jürg Gertsch, Sarah Meier, Natalie Tschopp, and Karl-Heinz Altmann*
}

\begin{abstract}
The search for improved cytotoxic agents continues to be an important line of modern anticancer drug discovery and a promising mechanistic approach towards this goal is the functional inhibition of cellular microtubules. Tubulin inhibitors are compounds which either stabilize or destabilize microtubules in vitro, leading to G2/M cell cycle arrest and apoptosis in cancer cells. While destabilizing agents, such as vinca alkaloids inhibit the assembly of $\alpha \beta$-tubulin heterodimers, stabilizing compounds like taxol induce the de novo formation of stable microtubules in vitro. In this study we have investigated a number of plant-derived compounds that have recently been reported to interact with the tubulin/microtubule system and to induce taxol-like effects. This includes the sesquiterpene lactones parthenolide and costunolide, the coumarin derivative ferulenol, and the jatrophane ester JTE1. In addition, we have screened a small natural product library (84 cytotoxic compounds) and 107 cytotoxic plant extracts in an assay system that allows the detection of both microtubule-stabilizing and -destabilizing agents in a 96-well setup within the same experimental format. None of the plant extracts inhibited or induced tubulin polymerization in vitro. From the compound library only the known plant-derived tubulin inhibitors vinblastine, colchicine, podophyllotoxin, chelidonine, rotenone, and taxol were identified as hits. Curcumin, which was recently reported to destabilize cellular microtubules, was inactive in our assay. Interestingly, rotenone, which is widely used as a mitochondrial respiration chain I inhibitor, potently inhibited microtubule assembly in vitro and showed higher affinity to $\alpha \beta$-tubulin than vinblastine, although it was significantly less cytotoxic. None of the plant-derived natural products that were recently reported to be microtubule-stabilizing agents were found to be active in our assay system. In conclusion, plant-derived natural products clearly represent an interesting and productive source for microtubule-destabilizing agents. In contrast, apart from taxol and related structures, no plant-derived natural product with potent in vitro microtubule-stabilizing properties has yet been identified.
\end{abstract}

Keywords: Microtubules · Plant natural products $\cdot$ Taxol $\cdot$ Tubulin inhibitors $\cdot$ Vinblastine

\section{Introduction and Background}

Cancer represents one of the most severe health problems worldwide and the development of improved therapeutic agents and more effective clinical strategies for cancer treatment are fields of utmost importance in drug discovery and clinical research. Tubulin inhibitors constitute an important group of cytotoxic anticancer drugs, with clinical applications in the treatment of a variety of cancer types, either as single agents or as part of different combination regimes. ${ }^{[1]}$ Tubulin inhibitors (also referred to as microtubule-interacting agents) can be grouped into two functional classes, namely compounds that inhibit

${ }^{\star}$ Correspondence: Prof. Dr. K.-H. Altmann Swiss Federal Institute of Technology (ETH) Zürich Institute of Pharmaceutical Sciences

ETH Hönggerberg, $\mathrm{HCl} \mathrm{H} 405$

$\mathrm{CH}-8093$ Zürich

Tel.: +41446337390

Fax: +41446331360

E-Mail: karl-heinz.altmann@pharma.ethz.ch the assembly of tubulin heterodimers into microtubule polymers ('tubulin polymerization inhibitors') and those that stabilize microtubules under normally destabilizing conditions ('microtubule stabilizers').[2] The latter also promote the assembly of $\alpha \beta$-tubulin heterodimers into microtubules (or microtubule-like polymers) and this effect is often used as a biochemical readout for a quantitative assessment of the interaction of microtubule-stabilizing agents with tubulin. The use of tubulin polymerization inhibitors such a vincristine and vinblastine in cancer therapy dates back more than 40 years (vincristine and vinblastine received FDA approval in 1963 and 1965, respectively, but they are still in clinical use even today), whereas the introduction of the microtubule-stabilizers taxol $\left(\right.$ Taxol $\left.^{\circledR}\right)$ and docetaxel (Taxotere $^{\circledR}$ ) into clinical practice took place only in 1993 and 1996, respectively. ${ }^{[3]}$ The microtubule-stabilizing properties of taxol were first recognized in 1979 by Susan Horwitz and co-workers, ${ }^{[4]}$ and for the following 16 years taxol and related analogs were the only compound class known to be associated with microtubule stabilization.
However, since 1995 a variety of other (nontaxane) natural products from diverse sources have been established to share taxol's ability to inhibit the depolymerization of microtubules (or to induce tubulin polymerization) and these discoveries have opened new perspectives for the development of new generations of taxol-like clinical anticancer agents. The most prominent representatives of this group of compounds include epothilones A and $\mathrm{B}$, discodermolide, eleutherobin, sarcodictyins A and B, laulimalide, FR182877 (also known as WS9885B and, more recently, cyclostreptin), peloruside A, and dictyostatin. ${ }^{[5]}$ Most notably, all potent microtubule stabilizers known today are natural products or derived from natural product leads. In contrast, several natural products as well as a number of small synthetic molecules are known, which act as efficient inhibitors of tubulin polymerization. ${ }^{[6]}$ A number of different microtubule-destabilizing compounds have been isolated from plants, including vinblastine and vincristine, while taxol and some related structures are the only known microtubule-stabilizing agents of plant ori- 
gin. At least this appeared to be the situation until recently, when a number of known plant natural products were reported in the literature to exhibit a taxol-like mechanism of action $^{[7-11]}$ (Fig. 1).

Given our long-standing interest in microtubule-interacting agents[5a,c,12] we were highly intrigued by these reports and we started to investigate the in vitro interactions of several plant secondary metabolites with the tubulin/microtubule system in our own laboratory. This has included the screening of a small library of cytotoxic natural products and plant extracts, but also several of the recently reported non-taxane microtubule stabilizers from plants. What should be noted in this context is that cell growth inhibition by tubulin inhibitors appears to be related to interference with microtubule dynamics and can occur without gross changes in the fraction of polymerized tubulin. ${ }^{[13,14]}$ While this finding provides a unifying mechanistic framework for the cellular effects of both microtubule-stabilizing as well as -destabilizing agents, it is clear that all established potent tubulin inhibitors exhibit unambiguous effects on tubulin polymerization or microtubule stability in vitro (due to direct interactions with the tubulin/microtubule system). These findings provide the conceptual basis for the experiments reported in this study.

\section{Assay System for Tubulin Inhibitor Screening}

Purified porcine brain tubulin was obtained according to the method of Castoldi and Popov. ${ }^{[15]}$ In order to minimize the use of protein material we developed an in vitro assay in which microtubule-stabilizing and -destabilizing compounds can be detected within a single experimental format in a 96-well setup in a plate reader (Fig. 2). The formation of tubulin oligomers and polymers (BRB80 buffer; $80 \mathrm{mM}$ PIPES, $1 \mathrm{mM} \mathrm{MgCl}, 1 \mathrm{mM}$ EGTA adjusted to $\mathrm{pH}$ 6.8 with $\mathrm{KOH}$ ) can be followed by a turbidity change at $\lambda=340 \mathrm{~nm} \cdot{ }^{[16]}$ During a first incubation period of $30 \mathrm{~min}$ the effect of test compounds on soluble $\alpha \beta$-tubulin is assessed in the absence of any polymerization stimulus (other than potentially exerted by the test compound). During this phase microtubule-stabilizing compounds, such as taxol, lead to an increase in OD $340 \mathrm{~nm}$ (Fig. 2), while no turbidity change is detectable for tubulin polymerization inhibitors (or completely inactive compounds).

After this first incubation period, $0.4 \mathrm{M}$ glutamate and $0.5 \mathrm{mM}$ guanosine triphosphate (GTP) are added, leading to a rapid induction of de novo microtubule formation. In this phase, microtubule-destabilizing compounds, such as vinblastine can be detected based on a reduced increase in OD $340 \mathrm{~nm}$ (Fig. 2). Compounds for which $\mathrm{IC}_{50} / \mathrm{EC}_{50}$

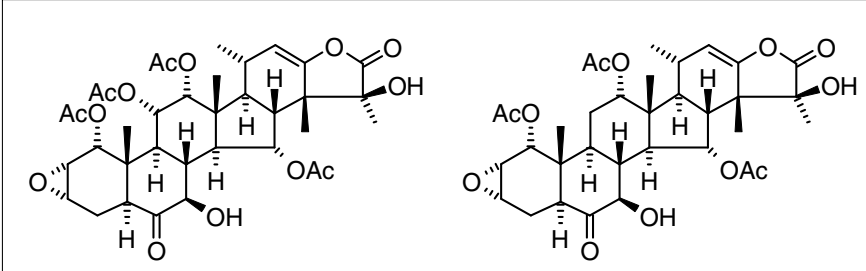

Taccalonolide A $\left(\mathrm{Ac}=\mathrm{CH}_{3} \mathrm{C}(\mathrm{O})\right) \quad$ Taccalonolide $\mathbf{E}\left(\mathrm{Ac}=\mathrm{CH}_{3} \mathrm{C}(\mathrm{O})\right)$<smiles>CN1c2ccccc2C(=O)N2CCc3c([nH]c4ccccc34)[C@H]21</smiles>

Evodiamine

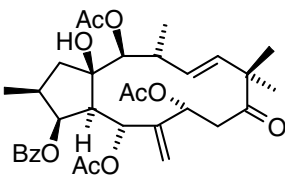

JTE1

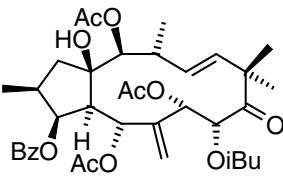

JTE2

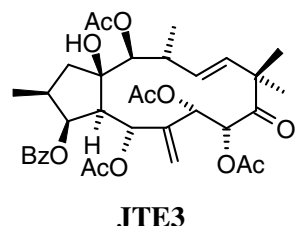

JTE3
$\left.\left(\mathrm{Ac}=\mathrm{CH}_{3} \mathrm{C}(\mathrm{O}) ; \mathrm{Bz}=\mathrm{C}_{6} \mathrm{H}_{5} \mathrm{C}(\mathrm{O})\right) ; \mathrm{iBu}=\left(\mathrm{CH}_{3}\right)_{2} \mathrm{CHC}(\mathrm{O})\right)$<smiles>CC(C)=CCC/C(C)=C/CC/C(C)=C/CC1=C(O)c2ccccc2CC1=O</smiles>

Ferulenol<smiles></smiles>

Parthenolide

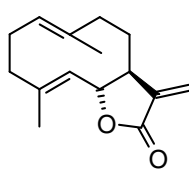

Costunolide
Fig. 1. Examples of plant-derived natural products that have been reported to exhibit microtubulestabilizing and/or tubulin-polymerizing activity[7-11] values (for inhibition or induction of tubulin polymerization, respectively) could be determined at 1:1 molar ratios of $\alpha \beta$-tubulin and test compound were considered as hits. This assay system proved to be suitable for the assessment of pure compounds as well as plant extracts.

\section{Putative Microtubule Stabilizers from Plants}

Although taxol, as the first microtubule stabilizer ever discovered, is a plant-derived natural product, only few other compounds from plant sources have been reported to

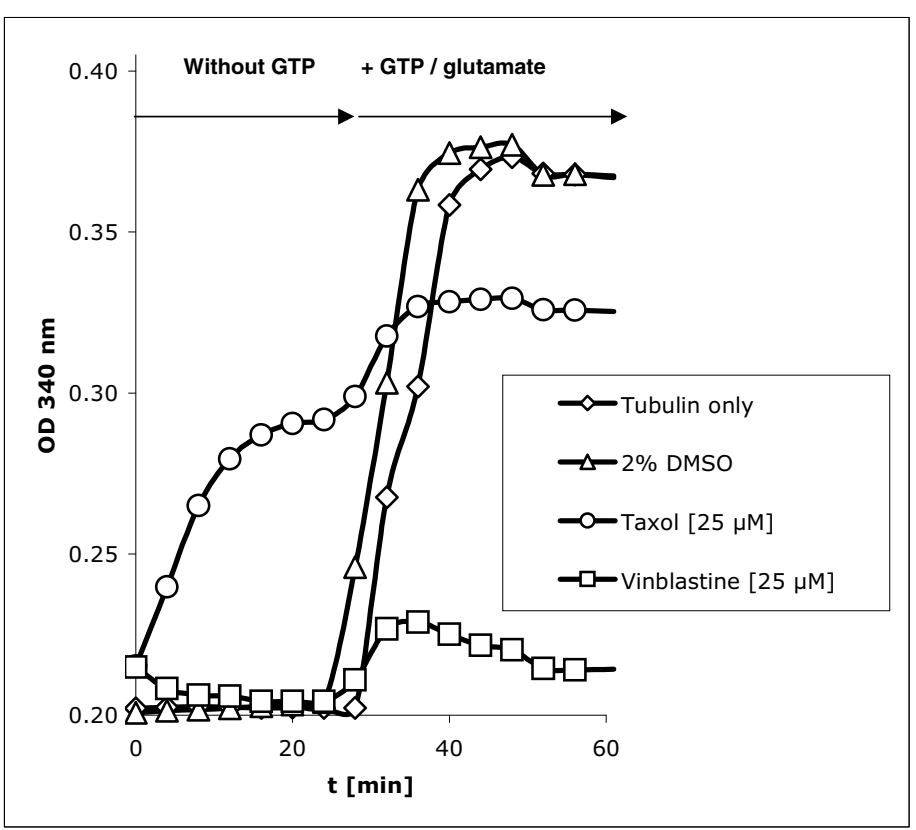

Fig. 2. Effects of vinblastine and taxol on tubulin polymerization in vitro: Purified $\alpha \beta$-tubulin $(60 \mu \mathrm{M})$ was incubated in BRB80 buffer and the optical density (OD) at $340 \mathrm{~nm}$ was measured over time. The experiment proceeds through two phases, which are distinguished by the absence or presence of GTP and glutamate. 
exhibit microtubule-stabilizing and/or tubulin-polymerizing activity. However, while some of these natural products produce cellular effects that are typical of microtubule-stabilizing agents, none of them so far has been reproducibly demonstrated to promote tubulin polymerization in vitro. Thus, in 2003 Mooberry and co-workers reported the plant steroids taccalonolides $\mathrm{A}$ and $\mathrm{E}$ (Fig. 1), which they had isolated from Tacca chantrieri (Taccaceae), to be "the first microtubule-stabilizing agents of plant origin since the discovery of taxol". [7] This conclusion was based on a number of cellular effects produced by these compounds at $\mu \mathrm{M}$ concentration levels, such as thickening of microtubules in A-10 cells, cell cycle arrest in $\mathrm{G} 2 / \mathrm{M}$ (with the formation of abnormal mitotic spindles, containing three or more spindle poles), and phosphorylation of the anti-apoptotic protein Bcl-2. In addition, taccalonolide $\mathrm{A}$ and $\mathrm{E}$ inhibited the proliferation of the human ovarian cancer cell line SK-OV-3 with $\mathrm{IC}_{50}$ values of $2.59 \mu \mathrm{M}$ and $0.99 \mu \mathrm{M}$, respectively (the $\mathrm{IC}_{50}$ for taxol in this cell line is $2.25 \mathrm{nM}$ ), but no data were presented in the work by Mooberry and coworkers ${ }^{[7]}$ on the effects of taccalonolide A and $\mathrm{E}$ on tubulin polymerization or microtubule binding in vitro. In a subsequent mechanistic study, Buey et al. ${ }^{[17]}$ found no evidence for taccalonolides $\mathrm{A}$ or $\mathrm{E}$ to induce tubulin polymerization in vitro even at high concentrations; at the same time, the compounds were not able in displacement experiments to compete with the binding of a fluorescent taxol analog (Flutax-2) to microtubules in vitro. The cellular effects of taccalonolides $\mathrm{A}$ and $\mathrm{E}$ thus appear not to be caused by a direct interaction of these compounds with the tubulin/microtubule system.

As for taccalonolides, cellular effects that are generally associated with microtubule-stabilizing agents have recently been reported for the alkaloid evodiamine (Fig. 1), ${ }^{[18]}$ which is one of the major active principles of the traditional Chinese herbal medicine "Wu-Chu-Yu", the dry unripe fruit of Evodia rutaecarpa (Juss.) Benth. Evodia rutaecarpa (Rutaceae) is associated with a broad range of pharmacological activities and these have recently been reviewed by Chen et al. ${ }^{[19]}$ Evodiamine was found to produce pronounced microtubule bundling in NCI/ADR-RES cells (at $1 \mu \mathrm{M}$ ) and to cause a significant shift in the equilibrium between soluble and polymerized tubulin to the polymerized form (at $10 \mu \mathrm{M}$ ). These findings strongly suggest that the antiproliferative activity of evodiamine against NCI/ADR-RES cells $\left(\mathrm{GI}_{50}\right.$ of $\left.0.59 \mu \mathrm{M}\right)$ is mediated, at least in part, through effects on the tubulin/microtubule system and that the compound may be a microtubule-stabilizing agent. This hypothesis receives further support from the fact that evodiamine treatment causes cell cycle arrest in G2/M, leads to phosphorylation of c-raf and $\mathrm{Bcl}-2$, and induces apoptosis. ${ }^{[18]}$ It must be emphasized, however, that the binding of evodiame to tubulin/microtubules and its ability to induce tubulin polymerization in vitro have not yet been investigated. It is thus still conceivable that the microtubule-associated effects of the compound in NCI/ADR-RES cells may not be the consequence of a direct interaction with the tubulin/microtubule system, but may originate in its interaction with an as yet unknown target (as appears to be the case with taccalonolides).

Apart from taccalonolides A and E, other putative microtubule inhibitors from plants that were investigated by Buey et al. as part of a comprehensive comparative study included jatrophane esters JTE1-JTE3 (Fig. 1). These compounds had been reported by Miglietta et al. in 2003 to be potent inducers of tubulin polymerization in vitro. ${ }^{[8]}$ Tubulin polymerization was only observed in the absence of $\mathrm{Ca}^{2+}$-ions (in contrast to taxol) and the polymers formed were highly unstable. However, under appropriate experimental conditions JTE1-JTE3 appeared to be equipotent with taxol in promoting tubulin polymerization and the microtubules formed were indistinguishable by electron microscopy from those formed with taxol. In contrast to these findings, Buey et al. ${ }^{[17]}$ could not find evidence for the induction of tubulin polymerization by JTE1-JTE3. We have investigated jatrophane ester JTE1 in our own assay system and, in agreement with the data of Buey et al., the compound did not induce tubulin polymerization un- der our experimental conditions (Table). Likewise, JTE1 in our hands did not cause mitotic arrest and it did not significantly inhibit the growth of PC-3 human prostate cancer cells at concentrations below $10 \mu \mathrm{M}$, both of which would be expected for a microtubule-stabilizing agent of even moderate potency. Compounds for which similar effects have been reported as for the jatrophane esters JTE1-JTE3 are ferulenol, a prenylated coumarol from Ferula communis L. (Umbelliferae), [9] parthenolide, a sesquiterpene lactone from the medicinal herb feverfew (Tanacetum parthenium (L.) Schultz Bip., Asteraceae), ${ }^{[10]}$ and costunolide, another sesquiterpene lactone from Saussurea lappa C.B. Clarke (Asteraceae $^{[11]}$ (Fig. 1). Quite remarkably, ferulenol under $\mathrm{Ca}^{2+}$-free conditions appeared to be equipotent with taxol in its ability to promote tubulin assembly and significant tubulin polymerization was found to occur even at ligand concentrations of $10 \mathrm{nM}$ for both compounds (at $c a$. $10 \mu \mathrm{M}$ tubulin concentration). As many previous studies have established that maximum tubulin polymerization with taxol is normally achieved at a 1:1 tubulin/taxol ratio, ${ }^{[20]}$ this finding is rather unusual. Due to our long-standing interest in microtubule-stabilizing agents and intrigued by the relative simplicity of the structures of the above compounds (Fig. 1), we have again investigated their tubulin-polymerizing effects and their cellular activity in our own assay systems. Unfortunately, experiments with ferulenol in our own laboratory showed no evidence for the

Table. Microtubule-related effects of plant-derived natural products

$\begin{array}{lllll}\text { Compound } & \begin{array}{l}\text { Cytotoxicity } \\ \mathrm{IC}_{50}[\mu \mathrm{M}]\end{array} & \begin{array}{l}\text { Tubulin Polymerisation } \\ \mathrm{IC}_{50}[\mu \mathrm{M}]\end{array} & K_{\mathrm{d}}[\mu \mathrm{M}]^{\mathrm{d}} & \begin{array}{l}\text { G2/M cell } \\ \text { cycle arrest }^{\mathrm{e}}\end{array} \\ \text { Chelidonine } & <2 & 15.7 \pm 2.7 & 14.8 \pm 3.9 & + \\ \text { Colchicine } & <0.05 & 12.5 \pm 2.8 & 3.2 \pm 1.3 & + \\ \text { Costunolide } & 1.2 \pm 0.5 & >100 & >50 & - \\ \text { Curcumin } & 8.9 \pm 1.4 & >100 & >50 & - \\ \text { Ferulenol } & >10 & >100 & >50 & - \\ \text { JTE1 } & >10 & >100 & >50 & - \\ \text { Parthenolide } & 0.43 \pm 0.11 & >100 & >50 & - \\ \text { Podophyllotoxin } & <0.05 & 7.2 \pm 1.5 & \text { n.d. } & + \\ \text { Rotenone } & 0.82 \pm 0.23 & 4.3 \pm 2.0 & 3.9 \pm 0.9 & - \\ \text { Taxol } & <0.005 & 3.9 \pm 1.1^{\mathrm{c}} & \text { n.d. } & + \\ \text { Vinblastine } & <0.005 & 5.3 \pm 1.7 & 11.2 \pm 2.7 & +\end{array}$

anhibition of proliferation of PC-3 cells after $72 \mathrm{~h}$ incubation with test compound. 'Inhibition of GTP-induced tubulin polymerization. ${ }^{c} \mathrm{EC}_{50}$ value for induction of tubulin polymerization. ${ }^{\mathrm{d}} K_{d}$ for binding to purified $\alpha \beta$-tubulin. (Determined according to the method of Lee et al. ${ }^{[21]}$ ). ${ }^{e} \mathrm{Cell}$ cycle arrest was determined in PC-3 cells at concentrations close to the $\mathrm{IC}_{50}$ value of the respective compound in the proliferation assay by propidium iodide staining in FACS. 
compound to induce tubulin polymerization in vitro (Table); likewise, the $\mathrm{IC}_{50}$ values for growth inhibition of the human cancer cell lines KB31, MCF7, HL60 (data not shown), or PC-3 (Table) were clearly in excess of 10 $\mu \mathrm{M}$ (the highest concentration tested in our experiments; $72 \mathrm{~h}$ exposure). Similar results were obtained with parthenolide and costunolide, neither of which was able to bind to purified tubulin from pig brain $\left(K_{\mathrm{d}}>50 \mu \mathrm{M}\right)$ or to induce tubulin polymerization under various conditions (Table). Based on our data the growth inhibitory effects of these two sesquiterpene lactones (Table) appear not to be caused by a taxol-like mechanism of action. The origin of the discrepancies between our own results (and those of Buey et al. ${ }^{[17]}$ ) and previous literature data is unclear at this point, but they may be related to differences in the experimental conditions employed. ${ }^{[22]}$ However, even if this were the case, it is clear that the in vitro microtubulestabilizing effects of the above compounds (if they exist) cannot be very robust. On the other hand, microtubule stabilization or, perhaps more precisely, the interference with microtubule dynamics could still be operative at the cellular level, where these effects could be mediated through interactions of the compounds with microtubuleassociated proteins rather than direct binding to tubulin/microtubules.

\section{Microtubule-Destabilizing Plant Natural Products}

In our plant-derived natural product library screen (84 cytotoxic compounds, including representatives from all major classes of plant natural products) several compounds were found to inhibit tubulin polymerization, all of which, however, were known microtubule destabilizers. Besides the well-established tubulin inhibitors colchicine and vinblastine, the benzophenanth- ridine alkaloid chelidonine from the Celandine poppy Chelidonium majus L. (Papaveraceae), and rotenone, an isoflavonoid from Derris spp. (Leguminosae), were identified as hits (Fig. 3).

Chelidonine and its analog sanguinarine were first identified as tubulin inhibitors by Wolff and Knipling in 1993,[23] who described the compound as a weak competitive inhibitor of colchicine. Chelidonine has subsequently been reported to cause mitotic arrest and to interact weakly with tubulin (inhibition of tubulin polymerization with an $\mathrm{IC}_{50}$ of $\left.24 \mu \mathrm{M}\right)$. ${ }^{[24]}$ Similar results were obtained in our own experiments, which demonstrated tubulin binding of the compound with a $K_{\mathrm{d}}$ of $14.8 \mu \mathrm{M}$ and also significant inhibition of tubulin polymerization $\left(\mathrm{IC}_{50}=\right.$ $15.7 \mu \mathrm{M}$ ) (Fig. 4, Table).

Overall, chelidonine exhibited all effects expected for a microtubule-destabilizing agent, but was only moderately cytotoxic in PC-3 prostate cancer cells (Table). The chelidonine analogs sanguinarine and dihydrosanguinarine (an in vivo metabolite of sanguinarine) ${ }^{[27]}$ were much less active in our assay system and did not score as screening hits. Likewise, sanguinarine, which has recently been reported to exert significant anti-tubulin effects in vitro, ${ }^{[28]}$ was a far less potent tubulin inhibitor than chelidonine in our experiments.

Rotenone (Fig. 3) is a well-known pesticide. ${ }^{[29]}$ The compound is widely used in cellular experiments as a mitochondrial respiration chain I inhibitor because it blocks electron transfer in NADH-Q dehydrogenases. ${ }^{[30]}$ Although rotenone was first shown to inhibit tubulin polymerization in $1978,{ }^{[25]}$ this effect was not further discussed in the scientific lit- erature until very recently, when it regained interest in the context of rotenone-induced Parkinson's disease. ${ }^{[31]}$ In our assay system rotenone potently inhibited in vitro tubulin assembly induced either by GTP (Fig. 4) or a variety of microtubule-stabilizing compounds, such as taxol, discodermolide or epothilones (data not shown). The $\mathrm{IC}_{50}$ for the inhibition of in vitro tubulin polymerization by rotenone was $4.3 \mu \mathrm{M}$, which is comparable with the $\mathrm{IC}_{50}$ of the potent tubulin inhibitor vinblastine $(5.3 \mu \mathrm{M})$. Our data further suggest that rotenone strongly binds to $\alpha \beta$-tubulin heterodimers with a $K_{\mathrm{d}}(3.9 \mu \mathrm{M})$ that is significantly lower than that obtained for vinblastine $(11.2 \mu \mathrm{M})$. However, in cellular systems, rotenone is only moderately cytotoxic in PC-3 prostate carcinoma cells $\left(\mathrm{IC}_{50}=0.82 \mu \mathrm{M}\right)$ and it does not cause $\mathrm{G} 2 / \mathrm{M}$ arrest at concentrations $<2 \mu \mathrm{M}$ (Table). As indicated above, rotenone is often employed as a biochemical research tool in cell-based experiments as a specific inhibitor of mitochondrial respiration at concentrations ranging from 2 to $15 \mu \mathrm{M} .{ }^{[30]}$ However, these concentrations may also affect microtubule function and this fact has not been widely appreciated.

Curcumin, the major component of turmeric (Curcuma longa L.) (Fig. 3), exhibits numerous beneficial medical effects, both in vitro and in vivo, including antitumor activity against several tumor types (for a recent review see ${ }^{[32]}$ ). Recently, the compound was also reported as a new anti-microtubule agent. ${ }^{[26]}$ Thus, curcumin was found to inhibit HeLa and MCF-7 cell proliferation in a concentration-dependent manner with $\mathrm{IC}_{50}$ values of $13.8 \mu \mathrm{M}$ and $12.0 \mu \mathrm{M}$, respectively. At the same time, the compound induced sig-

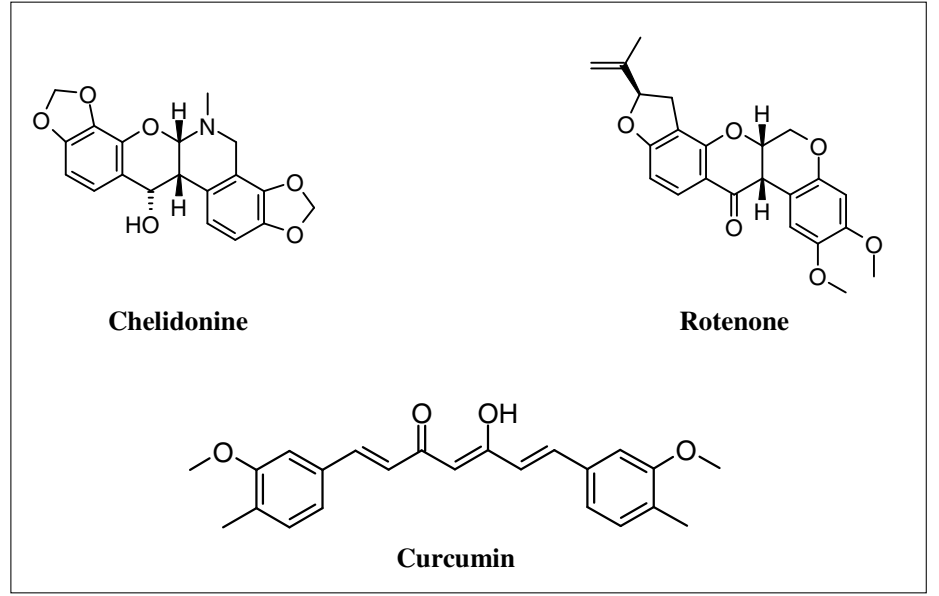

Fig. 3. Examples of plant-derived natural products that have been reported to exhibit microtubule-destabilizing activity: Chelidonine, ${ }^{[23,24]}$ rotenone, ${ }^{[25]}$ and curcumin ${ }^{[26]}$

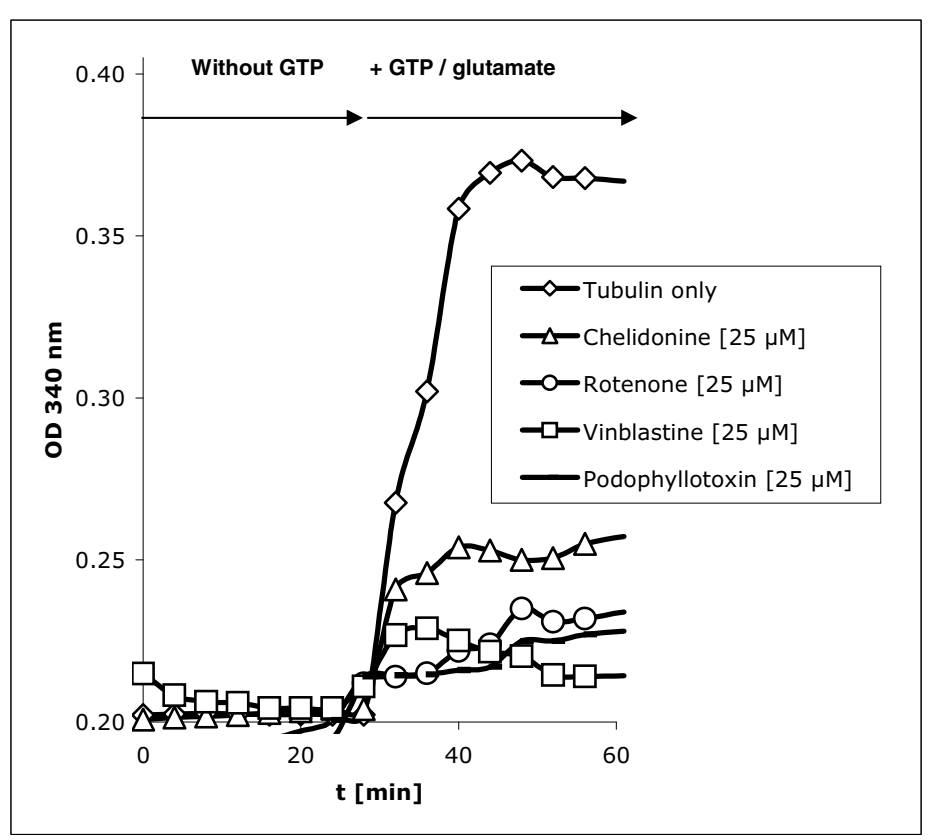

Fig. 4. Inhibition of tubulin polymerization by chelidonine, rotenone, podophyllotoxin, and vinblastine. Purified $\alpha \beta$-tubulin $(60 \mu \mathrm{M})$ was incubated in BRB80 buffer and the optical density (OD) at $340 \mathrm{~nm}$ was measured over time in the presence of test compound. 
nificant depolymerization of interphase microtubules and mitotic spindle microtubules at concentrations $>10 \mu \mathrm{M}$. Investigation of the interaction of curcumin with $\alpha \beta$-tubulin revealed a single binding site with a dissociation constant of $2.4 \mu \mathrm{M}$ and the binding of curcumin to tubulin induced a protein conformational change. ${ }^{[26]}$ As shown in the Table, curcumin did not score as a tubulin inhibitor in our assay system. While this is indicative of a lack of robust effects on tubulin, it is still possible that the effects of curcumin on cellular microtubules at high concentrations (and the associated antiproliferative effects), are mediated indirectly, i.e. without binding to tubulin or microtubules.

\section{Screening of a Plant Extract Library}

In addition to the above small plantderived natural product library, 107 cytotoxic extracts from different European and tropical plants $(\mathrm{MeOH}$ or dichloromethane extracts from dried plant material) were tested in our screening assay for tubulin inhibition. $100 \mu \mathrm{g} / \mathrm{ml}$ of extract in $2 \%$ DMSO vehicle was added to $6 \mathrm{mg} / \mathrm{ml}(60 \mu \mathrm{M})$ of purified $\alpha \beta$-tubulin heterodimer. The concentration employed for the assay was based on results with a positive marine sponge extract, which reproducibly induced tubulin polymerization at a concentration of $50 \mu \mathrm{g} /$ $\mathrm{ml}$. Unfortunately, none of the plant extracts showed any measurable activity under these conditions. Whether these findings simply reflect the scarcity of tubulin inhibitors in plants or whether they may be present in concentrations that are too low to produce a robust response in our assay system remains to be seen.

\section{Conclusions}

Using a bimodal validated assay system we have performed a small screen for plantderived tubulin inhibitors. Hits from a plant natural product library were further analyzed in related assays, in order to determine their affinity to tubulin and their antiproliferative effects. As tubulin inhibitors at concentrations close to their $\mathrm{IC}_{50}$ value typically lead to G2/M cell cycle arrest this parameter was also analyzed. As expected, taxol, vinblastine, colchicine, and podophyllotoxin showed the typical effect pattern of tubulin inhibitors. Chelidonine and rotenone clearly bound to $\alpha \beta$-tubulin heterodimers and functionally inhibited GTP-induced microtubule assembly, but both compounds were only moderately cytotoxic and did not lead to G2/M arrest in PC 3 cells in the concentration range tested (Table). While several known microtubule-destabilizing compounds were identified as hits, none of the recently reported microtubule-stabilizing compounds with 'a taxol-like mechanism' showed a significant effect in our experiments. Moreover, neither sanguinarine nor curcumin appeared to be true microtubule-destabilizing agents. While the discrepancy between these findings and previous literature reports are difficult to interpret, they may be related to the potency requirements associated with our assay system. As all tubulin inhibitors in clinical use (taxol, vinblastine) or at various stages of clinical development (e.g. epothilone B and several analogs thereof) show potent and robust anti-tubulin effects in vitro, which are a consequence of direct interactions with tubulin, our assay conditions were chosen such as to detect compounds with similar properties. Thus, modulatory compounds with weak or even moderate binding affinity to tubulin may not have been detected in our screen. Likewise, compounds affecting the stability or dynamics of cellular microtubules through indirect mechanisms would not have scored as hits. Such compounds could still be of interest for drug discovery research, but they could not be classified as tubulin inhibitors in a strict sense. While the likelihood of finding 'another taxol' (i.e. a compound with the same molecular mechanism of action as taxol) of plant origin may be low, plants may still serve as a potential source for new microtubule-destabilizing compounds with potent anticancer activity.

Received: April 9, 2007

[1] See for example: a) T. M. Mekhail, M. Markman, Expert Opin. Pharmacother. 2002, 3, 755; b) C. Obasaju, G. R. Hudes, Hematology/Oncology Clinics of North America 2001, 15, 525.

[2] E. Hamel, Med. Res. Rev. 1996, 16, 207.

[3] E. K. Rowinsky, Annu. Rev. Med. 1997, 48, 353.

[4] P. B. Schiff, J. Fant, S. B. Horwitz, Nature 1979, 277, 665.

[5] For recent reviews on microtubule-stabilizing agents see: a) K.-H. Altmann, J. Gertsch, Nat. Prod. Rep. 2007, 24, 327; b) D. C. Myles, Ann. Rep. Med. Chem. 2002 , 37, 125; c) K.-H. Altmann, Curr. Opin. Chem. Biol. 2001, 5, 424

[6] a) E. von Angerer, Curr. Opin. Drug Discov. Dev. 2000, 3, 575; b) H. Prinz, Expert Rev. Anticancer Ther. 2002, 2, 695.

[7] T. Tinley, D. A. Randall-Hlubek, R. M. Leal, E. M. Jackson, J. W. Cessac, J. C. Quada, Jr., T. K. Hemscheidt, S. L. Mooberry, Cancer Res. 2003, 63, 3211.

[8] A. Miglietta, L. Gabriel, G. Appendino, C. Bocca, Cancer Chemother. Pharmacol. 2003, 51, 67.

[9] C. Bocca, L. Gabriel, F. Bozzo, A. Miglietta, Planta Med. 2002, 68, 1135.

[10] A. Miglietta, F. Bozzo, L. Gabriel, C. Bocca, Chem.-Biol. Interact. 2004, 149, 165.

[11] C. Bocca, L. Gabriel, F. Bozzo, A. Miglietta, Chem.-Biol. Interact. 2004, 147, 79.
[12] a) K.-H. Altmann, B. Pfeiffer, S. Arseniyadis, B. A. Pratt, K. C. Nicolaou, ChemMedChem 2007, 2, 397; b) F. Feyen, J. Gertsch, M. Wartmann, K.-H. Altmann, Angew. Chem., Int. Ed. 2006, 45, 5880; c) F. Cachoux, T. Isarno, M. Wartmann, K.-H. Altmann, Synlett 2006, 1384; d) G. Bold, S. Wojeik, G. Caravatti, R. Lindauer, C. Stierlin, J. Gertsch, M. Wartmann, K.-H. Altmann, ChemMedChem 2006, 1, 37; e) F. Cachoux, T. Isarno, M. Wartmann, K.-H. Altmann, ChemBioChem 2006, 7, 54; f) F. Cachoux, T. Isarno, M. Wartmann, K.-H. Altmann, Angew. Chem., Int. Ed. 2005, 44, 7469.

[13] M. A. Jordan, L. Wilson, Nature Rev., Cancer 2004, 4, 253.

[14] M. A. Jordan, Curr. Med. Chem.: Anti-Cancer Agents 2002, $2,1$.

[15] M. Castoldi, A.V. Popov, Protein Expr. Purif. 2003, 32, 83.

[16] H. Dong, Y. Z. Li, W. Hu, Assay Drug Dev. Tech. 2004, 6, 621 .

[17] R. M. Buey, I. Barasoain, E. Jackson, A. Meyer, P. Giannakakou, I. Paterson, S. Mooberry, J. M. Andreu, J. F. Diaz, Chem. Biol. 2005, 12, 1269.

[18] C.-H. Liao, S.-L. Pan, J.-H. Guh, Y.-L. Chang, H.-C. Pai, C.-H. Lin, C.-M. Teng, Carcinogenesis 2005, 26, 968.

[19] C.-F. Chen, W.-F. Chiou, C.-J. Chou, J.-F. Liao, L.-C. Lin, G.-J. Wang, Y.-F. Ueng, Chinese Pharm. J. 2002, 54, 419.

[20] J. F. Diaz, J. M. Andreu, Biochemistry 1993, 32, 2747.

[21] J. C. Lee, D. Harrison, S. N. Timasheff, $J$. Biol. Chem. 1975, 250, 9276.

[22] E. Hamel, D. L. Sackett, D. Vourloumis, K. C. Nicolaou, Biochemistry 1999, 38, 5490.

[23] J. Wolff, L. Knipling, Biochemistry 1993, 32, 13334.

[24] A. Panzer, A. M. Joubert, P. C. Bianchi, E. Hamel, J. C. Seegers, Eur. J. Cell. Biol. 2001, 80, 111.

[25] L. E. Marshall, R. H. Himes, Biochim. Biophys. Acta 1978, 543, 590.

[26] K. K. Gupta, S. S. Bharne, K. Rathinasamy, N. R. Naik, D. Panda, FEBS J. 2006, 273, 5320.

[27] Z. Dvorak, V. Simanek, Curr. Drug. Metab. 2007, 8, 173 .

[28] M. Lopus, D. Panda, FEBS J. 2006, 273, 2139.

[29] M. B. Isman, Annu. Rev. Entomol. 2006, $51,45$.

[30] P. Lummen, Biochim. Biophys. Acta 1998, 1364, 287.

[31] G. U. Hoglinger, W. H. Oertel, E. C. Hirsch, J. Neural. Transm. Suppl. 2006, 70, 269.

[32] R. L. Thangapazham, A. Sharma, R. K. Maheshwari, AAPS J. 2006, 8, E443. 